\title{
Equivalent Air Spring Suspension Model for Quarter-Passive Model of Passenger Vehicles
}

\author{
Haider J. Abid, ${ }^{1}$ Jie Chen, ${ }^{2}$ and Ameen A. Nassar ${ }^{3}$ \\ ${ }^{1}$ Department of Mechanical Engineering, Thi-Qar University, Nasiriyah, Iraq \\ ${ }^{2}$ Department of Mechanical, Aerospace and Civil Engineering, Brunel University, Uxbridge UB8 3PH, UK \\ ${ }^{3}$ Department of Mechanical Engineering, Basrah University, Basrah, Iraq
}

Correspondence should be addressed to Haider J. Abid; haider-jabaur@eng.utq.edu.iq

Received 15 January 2015; Revised 19 April 2015; Accepted 20 April 2015

Academic Editor: Majid Ghassemi

Copyright (C) 2015 Haider J. Abid et al. This is an open access article distributed under the Creative Commons Attribution License, which permits unrestricted use, distribution, and reproduction in any medium, provided the original work is properly cited.

\begin{abstract}
This paper investigates the GENSIS air spring suspension system equivalence to a passive suspension system. The SIMULINK simulation together with the OptiY optimization is used to obtain the air spring suspension model equivalent to passive suspension system, where the car body response difference from both systems with the same road profile inputs is used as the objective function for optimization (OptiY program). The parameters of air spring system such as initial pressure, volume of bag, length of surge pipe, diameter of surge pipe, and volume of reservoir are obtained from optimization. The simulation results show that the air spring suspension equivalent system can produce responses very close to the passive suspension system.
\end{abstract}

\section{Introduction}

Suspension system design is a challenging task for the automobile designers in view of multiple control parameters, complex objectives (often conflicting), and stochastic disturbances. The problems stem from the wide range of operating conditions created by varying road conditions, vehicle speed, and load [1]; in general, the road handling and safety rules request harsh suspensions, while the passengers comfort feeling requires a soft damping. There are three types of suspension system: passive systems, semiactive systems, and active systems. Each of the type of suspension has different advantages and disadvantages. Passive suspension systems are subject to various tradeoffs when they are excited across a large frequency bandwidth [2], the disadvantage of a semiactive suspension where the system can be controlled only in one direction: opposite to the velocity of the damper extension [3]. The active vibration control has the disadvantages of complexity and high-energy consumption. The air spring suspension systems can be used to overcome these difficulties. The air spring system is well known for its low transmissibility coefficients and its ability to vary load capacities with only the change of the gas pressure within the springs. Air springs can be used for a mechatronic approach in suspension design because of their ability to provide a controlled variable spring rate and they offer simple and inexpensive automatic leveling.

One of the advantages of air springs is that the energystorage capacity of air is far greater per unit weight than that of mechanical spring material, such as steel. Because of the efficient potential energy storage of springs of this type, their use in a vibration-isolation system can result in a natural frequency for the system which is almost 10 times lower than for a system employing vibration isolators made from steel springs [4]. This leads to the applications where low frequency vibration isolation is necessary [5]. Air springs have not only lower resonance frequencies but also smaller over-all length than mechanical springs with equivalent characteristics [6]. The ability to change the load carrying capacity simply by changing the air pressure rather than changing out the air spring is a major advantage that air springs have over steel springs. The air spring is mainly used in commercial vehicles, but lately it is also used in higher classes of passenger vehicles.

As discussed above, the air spring suspension has a number of advantages in real application. However the design 
suspension system with air springs has been studied extensively. On the contrary, the design and analysis of the passive suspension system are fully established. Therefore, the air spring suspension system design problem can be converted to a model which produces suspension performance the same as a passive suspension system when using it without active controller or it can produce more efficient suspension system when use it with active controller. It is possible to convert a passive suspension system to an air spring suspension system and vice versa [7-12]. The equivalence means that both systems have the similar suspension response for the same road profile inputs.

There have been some researches on the use of air spring for suspension systems. For example, Toyofuku et al. showed that the auxiliary chamber has a smaller effect on the system [13] in high frequencies. Bhave studied the effects of pitch interconnection on vehicle performance and ride comfort by using completed parametric modeling [14]. Crolla and Ramsbottom made some improvements in performance for roll behavior of vehicle when he used electronically controlled pneumatic suspension [15]. Xiao et al. developed force-deflection relationship based on experimental data of nonlinear air spring model, where the sliding mode controller for quarter car model is used for the half car model of a vehicle suspension [16]. The finite element method was used to analyse the air spring stiffness by Wu et al. [17]. Moreover, the paper [17] compared the stiffness of equivalent of air spring model with stiffness of original model and discussed the relationship between inherent frequency and initial pressure, between air spring stiffness and auxiliary chamber, between air spring stiffness and different initial pressure. The pressure of air supplied to the electropneumatic pressure regulator was controlled by regulating the voltage provider by Bhandari and Subramanian [18]. Bruni et al. investigated the dynamic characteristics of an air spring suspension with control [19].

The main objective of this study is to obtain an air spring suspension system which can replicate the passive suspension system in terms of the suspension performance. In this research, an air spring suspension system is to be found which can produce the performance better than VAMPIC model [20] under the simulated quasistatic stiffness of the suspension. In the following part of the paper, the mathematical models for both air spring and passive suspension are presented in Section 2 and the optimization method is used to find air spring suspension model parameters in Section 3.

\section{Air Suspension System Mathematical Model and Its Passive Suspension System Equivalence}

2.1. Air Suspension System. The basis for mathematical models of air springs is to measure its mechanical properties. The mechanical behavior of air springs is often very complicated. The behavior is mainly based on fluid dynamic and thermodynamic mechanisms, where important quantities in such mechanisms are pressure, volume, temperature, mass flow rate, density, and energy of the air as well as shape of the air volume. For most air springs, these quantities should

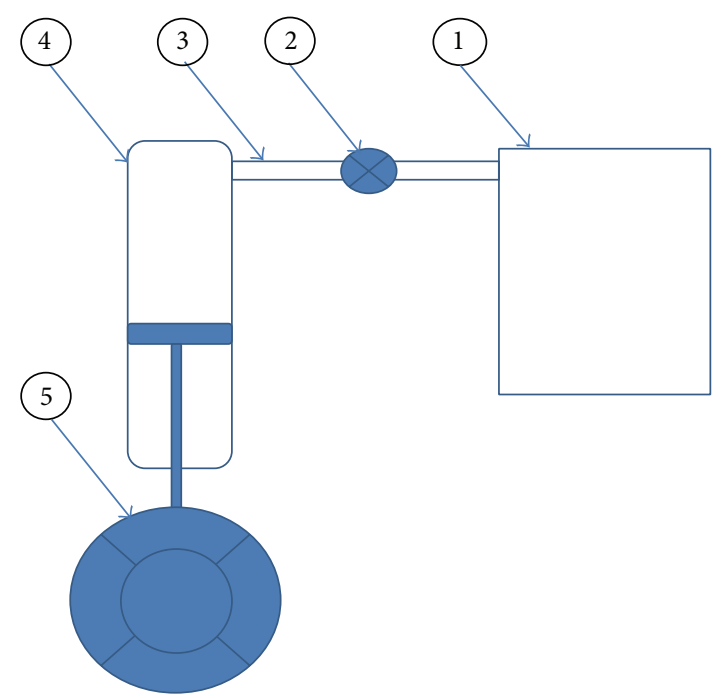

FIGURE 1: Air spring suspension system: (1) reservoir, (2) controlled valve, (3) surge pipe, (4) air bag, and (5) tire.

be expressed for both the air spring itself and its reservoir volume, as shown in Figure 1.

2.2. Air Spring Modeling. There are many different kinds of air spring models, such as a simple model for vertical air spring dynamics (Nishimura [6], VAMPIRE [21], SIMPAC [22], and GENSYS $[23,24])$. The air spring system as illustrated in Figure 1 consists of an air bag connected to a reservoir by a pipeline system and a controlled valve. The system's stiffness can be changed. The modeling of an air spring, presented here, does not take in consideration the leveling system because these changes are very slow. The mathematical models incorporate the stiffness and the damping characteristics of the air spring. Under the vibrations, the behavior of the compressed air within the air spring system is polytropic. The minimal stiffness is reached when there is an isothermal change of the gas state (for frequencies $f<$ $0.1 \mathrm{~Hz}$ ), and the maximal stiffness is associated with adiabatic state change (for frequencies $f>3 \mathrm{~Hz}$ ). The analysis of the vehicle vertical dynamics shows a special interest around the frequency domain from 0 to $20 \mathrm{~Hz}$ [6].

In order to consider the change in the gas state in the two volumes, an approximation has been introduced by implementing a mechanical barrier (fictive piston) in the pipeline. The mechanical barrier is considered to be with neglected mass and equivalent fluid mass that is moving through the pipeline is added to the barrier [5]. This approximation is justified because small amount of fluid oscillates between the two volumes.

The following analysis follows the method of calculation in [25] with the simplified air spring system shown in Figure 2. After a defection the new air bag volume and new reservoir volume with polytropic process, we get

$$
\begin{aligned}
& \because V_{b}=V_{\mathrm{bi}}-z A_{e}+z_{\mathrm{fp}} A_{s} \\
V_{r} & =V_{\mathrm{ri}}-z_{\mathrm{fp}} A_{s},
\end{aligned}
$$




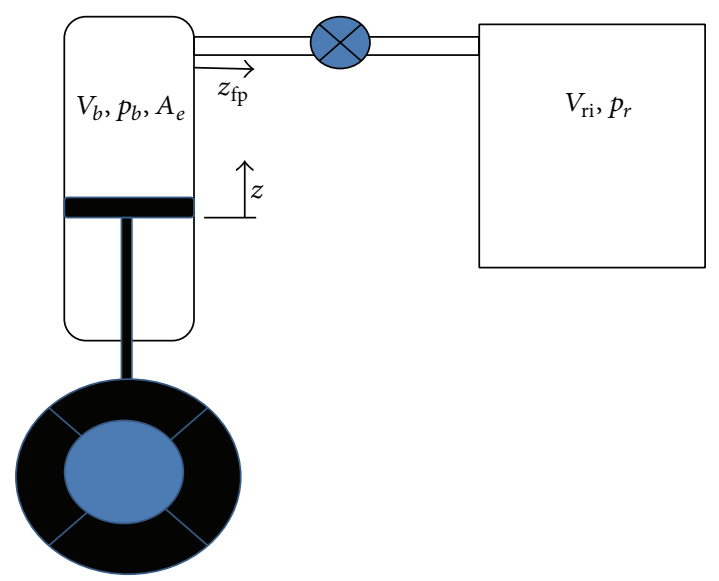

FIgURE 2: Modeling of air suspension spring.

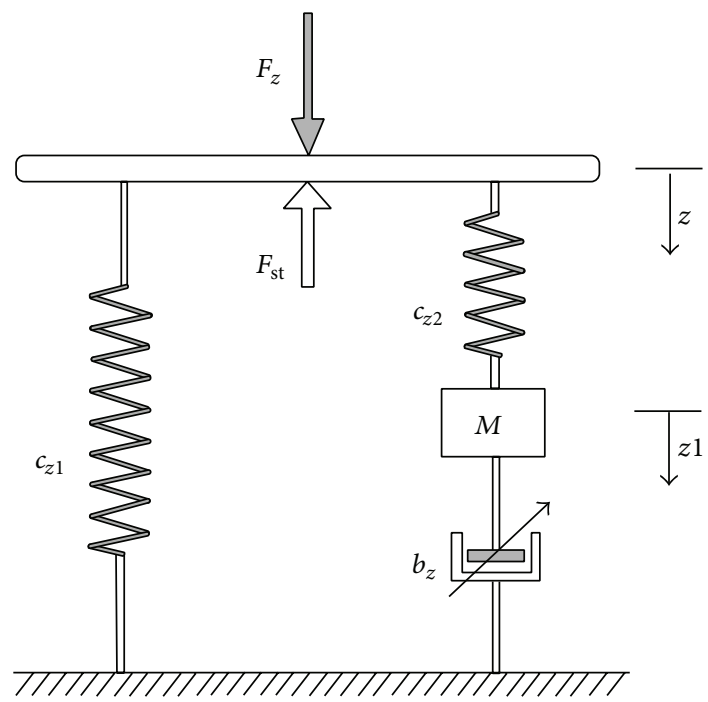

Figure 3: The mechanical model of air suspension system [6].

where $z$ is the deflection of air bag. $z_{\mathrm{fp}}$ is the the displacement of air in surge pipe. $A_{e}$ is the the effective area of air bag. $A_{s}$ is the the cross section area of the pipeline. $V_{\mathrm{bi}}$ is the the initial volume of air bag. $V_{\mathrm{ri}}$ is the the initial volume of reservoir.

The GENSYS model of the air suspension system as shown in Figure 3 has polytrope gas state change [6]. For this mode, the static load and the stiffness constants $C_{z 1}, C_{z 2}, M$, and $b_{z}$ can be identified as

$$
\begin{aligned}
C_{z 1} & =\frac{p_{i} A_{e}^{2} n}{V_{\mathrm{bi}}+V_{\mathrm{ri}}} \\
C_{z 2} & =\frac{p_{i} A_{e}^{2} n}{V_{\mathrm{bi}}+V_{\mathrm{ri}}} \frac{V_{\mathrm{ri}}}{V_{\mathrm{bi}}}=C_{z 2} \frac{V_{\mathrm{ri}}}{V_{\mathrm{bi}}} \\
M & =l_{s} A_{s} \rho\left(\frac{A_{e}}{A_{s}} \frac{V_{\mathrm{ri}}}{V_{\mathrm{bi}}+V_{\mathrm{ri}}}\right)^{2} .
\end{aligned}
$$

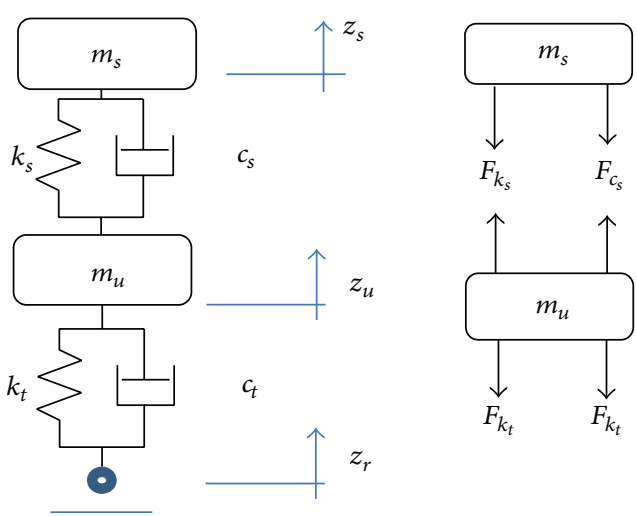

FIGURE 4: Quarter-car model and relevant free body diagram.

The model parameter $b_{z}$ is related to the velocity over the damper $\left(b_{z}\right)$ and not related to the velocity in the surge pipe. According to [23], the vertical viscous force is written as

$$
F_{v z}=C_{z 2}\left(z-w_{s}\right)=b_{z}\left|\dot{w}_{s}\right|^{\beta} \operatorname{sign}\left(\dot{w}_{s}\right)+M \ddot{w}_{s} .
$$

The above expression can be rewritten as

$$
M \ddot{w}_{s}=C_{z 2}\left(z-w_{s}\right)-b_{z}\left|\dot{w}_{s}\right|^{\beta} \operatorname{sign}\left(\dot{w}_{s}\right) .
$$

The relationship between the nonlinear damping $C_{z \beta}$ and $C_{s}$ is

$$
b_{z}=b_{s} k_{w z}^{1+\beta}=b_{s}\left(\frac{A_{e}}{A_{s}} \frac{V_{\mathrm{ri}}}{V_{\mathrm{bi}}+V_{\mathrm{ri}}}\right)^{1+\beta} .
$$

The value of $b_{s}$ can be calculated from the air damping occur in all system. The total pressure loss in a typical surge pipe occurs due to the loss of energy as major and minor fluid losses. The source of these energy losses is the abrupt enlargements and contractions where the air bag and reservoir joins the surge pipe, pipe friction, the number of pipe bends, and the loss in controlled valve (which is used with future study and it is not included with the determination of loss in this study). This gives that the total loss coefficient contains the following parts:

$$
\begin{aligned}
& b_{s}=\frac{1}{2} \cdot \rho_{i} \cdot b_{\mathrm{st}} \cdot A_{s} \\
& b_{\mathrm{st}}=b_{\mathrm{fr}}+b_{\mathrm{en}}+b_{c}+b_{b},
\end{aligned}
$$

where $b_{\mathrm{st}}$ is the is the total loss coefficient, $b_{\mathrm{fr}}$ is the loss coefficient due to friction, $b_{\mathrm{en}}$ is the loss coefficient due to enlargement, $b_{c}$ is the loss coefficient due to contraction, and $b_{b}$ is the loss coefficient due to bends in the pipe.

2.3. Mathematical Model of Passive Suspension System. The quarter car model of passive suspension system of vehicle is shown in Figure 4. It can be a simplified model with lumped masses and their relevant elements. In this study, the fundamental parameters of a suspension system can be defined by this model. 


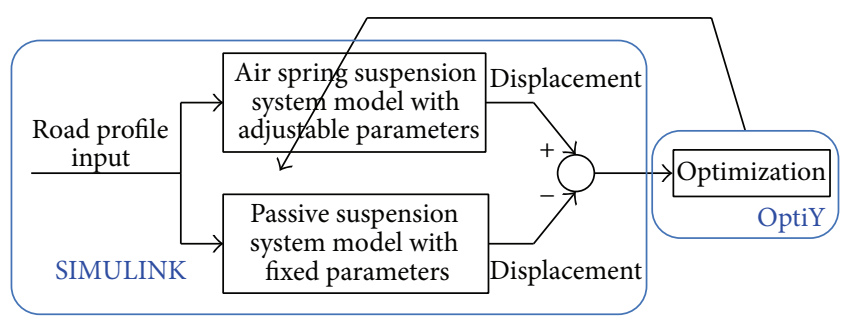

FIGURE 5: Finding equivalent model using SIMULINK simulation and OptiY optimization.

Nonlinear equations of the sprung mass and unsprung mass motions can be derived in two parts as follows [26].

Sprung mass equation:

$$
\begin{aligned}
m_{s} \ddot{z}= & -k_{s}\left(z_{s}-z_{u}\right)-\zeta k_{s}\left(z_{s}-z_{u}\right)^{3}-c_{s}\left(\dot{z}_{s}-\dot{z}_{u}\right) \\
& -\zeta c_{s}\left(\dot{z}_{s}-\dot{z}_{u}\right)^{2} \operatorname{sgn}\left(\dot{z}_{s}-\dot{z}_{u}\right) .
\end{aligned}
$$

Unsprung mass equation:

$$
\begin{aligned}
m_{u} \ddot{z}_{u}= & k_{s}\left(z_{s}-z_{u}\right)+\zeta k_{s}\left(z_{s}-z_{u}\right)^{3}+c_{s}\left(\dot{z}_{s}-\dot{z}_{u}\right) \\
& +\zeta c_{s}\left(\dot{z}_{s}-\dot{z}_{u}\right)^{2} \operatorname{sgn}\left(\dot{z}_{s}-\dot{z}_{u}\right)-k_{t}\left(z_{u}-z_{r}\right) \\
& -\zeta k_{t}\left(z_{u}-z_{r}\right)^{3}-c_{t}\left(\dot{z}_{u}-\dot{z}_{r}\right) \\
& -\zeta c_{t}\left(\dot{z}_{u}-\dot{z}_{r}\right)^{2} \operatorname{sgn}\left(\dot{z}_{u}-\dot{z}_{r}\right),
\end{aligned}
$$

where $F_{k_{s}}$ is the nonlinear force of coil springs $(\mathrm{N}) . F_{c_{s}}$ is the nonlinear forces of damper $(\mathrm{N}) . F_{k_{t}}$ is the the spring force of tire $(\mathrm{N}) . F_{c}$ is the the damping force of tire $(\mathrm{N}) \cdot m_{s}$ is the mass of vehicle's body $(\mathrm{kg}) . m_{u}$ is the mass of wheel $(\mathrm{kg})$. $k_{s}$ is the stiffness of spring $(\mathrm{N} / \mathrm{m}) . k_{t}$ is the stiffness of tire $(\mathrm{N} / \mathrm{m}) \cdot c_{s}$ is the damping coefficient of damper $(\mathrm{N} \cdot \mathrm{s} / \mathrm{m}) \cdot c_{t}$ is the damping coefficient of tire $(\mathrm{N} \cdot \mathrm{s} / \mathrm{m}) . z_{s}$ is the displacement of vehicle's body $(\mathrm{m}) . z_{u}$ is the displacement of wheel $(\mathrm{m})$. $z_{r}$ is the displacement of road profile $(\mathrm{m}) . \zeta$ is the empirical parameter

\section{Obtain Equivalent Air Spring Suspension Model Using Optimization}

The idea of equivalent model is to find an air spring suspension system configuration which produces the same suspension performance (displacement) as a passive suspension system count part with the same road profile inputs (if the passive mode is selected that means without controller). This is achieved by finding air spring system model parameters by minimizing the performance difference.

The process of obtaining the equivalent model is illustrated by Figure 5 where the response of both air spring suspension and passive suspension models are simulated using SIMULINK. The OptiY optimization program is used to adjust air suspension model parameters so that the response difference is minimized. The air suspension model parameters to be found are initial pressure in system, volume of bag, length of surge pipe, diameter of surge pipe, and volume
TABLE 1: The lower bound and the upper bound of the constraint parameters.

\begin{tabular}{lccc}
\hline Parameter & $\begin{array}{c}\text { Lower } \\
\text { bound }\end{array}$ & $\begin{array}{c}\text { Upper } \\
\text { bound }\end{array}$ & Unit \\
\hline $\begin{array}{l}\text { Initial pressure (in bag and } \\
\text { reservoir) }\end{array}$ & 100000 & 700000 & $\mathrm{kPa}$ \\
Bag diameter & 0.05 & 0.2 & $\mathrm{~m}$ \\
Bag height & 0.1 & 0.75 & $\mathrm{~m}$ \\
Reservoir volume & 0.01 & 0.3 & $\mathrm{~m}^{3}$ \\
Length of surge pipe & 1 & 5 & $\mathrm{~m}$ \\
Diameter of surge pipe & 0.003 & 0.025 & $\mathrm{~m}$ \\
\hline
\end{tabular}

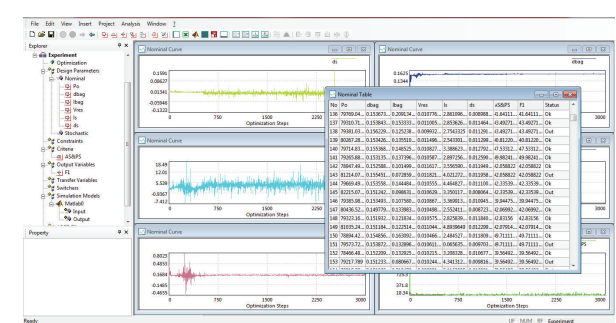

Figure 6: The results of OptiY software with MATLAB/Simulink.

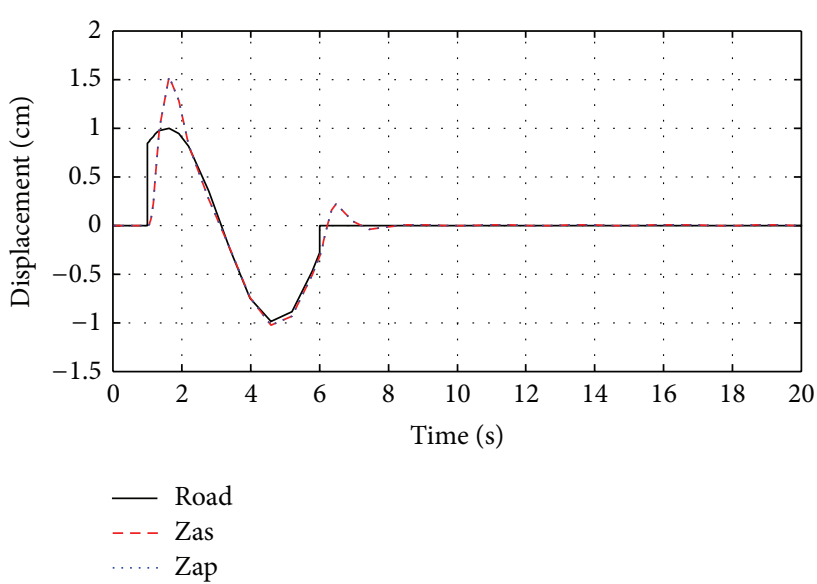

FIGURE 7: The response of optimization technique with sine wave road profile.

of reservoir. The optimization is a constraint optimization problem where the design parameter constraints are given in Table 1.

The parameter values of the quarter passive vehicle model used in the simulation are taken from [27]. The road profile used in this study is sine, square, and saw tooth waves with amplitude $10 \mathrm{~cm}$ and frequency of $1 \mathrm{~Hz}$. The optimization technique is implemented with 3000 attempts and the SIMULINK simulate the systems with 20 seconds period. The optimal parameters found are presented in Table 2.

The system responses for passive and optimized air spring suspension systems are presented in Figure 6. The response of equivalent air spring suspension system with sine wave road profile, square road profile, and random road profile are shown in Figures 7-9. 
TABLE 2: The numerical values of the passive suspension system.

\begin{tabular}{|c|c|c|c|}
\hline Notations & Description & Values & Units \\
\hline$K 1, K 2$ & Front-left and front-right suspension stuffiness, respectively & 19960 & $\mathrm{~N} / \mathrm{m}$ \\
\hline$K 3, K 4$ & Rear-left and Rear-right suspension stuffiness, respectively & 17500 & $\mathrm{~N} / \mathrm{m}$ \\
\hline$k 1-k 4$ & Front-left and front-right and rear-right and rear-left tire stuffiness, respectively & 175500 & $\mathrm{~N} / \mathrm{m}$ \\
\hline$C 1, C 2$ & Front-left and front-right suspension damping, respectively & 1290 & $\mathrm{~N} \cdot \mathrm{s} / \mathrm{m}$ \\
\hline$C 3, C 4$ & Rear-left and rear-right suspension damping, respectively & 1690 & $\mathrm{~N} \cdot \mathrm{s} / \mathrm{m}$ \\
\hline$c 1-c 4$ & Front-left and front-right and rear-right and rear-left tire damping, respectively & 14.6 & $\mathrm{~N} \cdot \mathrm{s} / \mathrm{m}$ \\
\hline$M$ & Sprung mass & 1460 & $\mathrm{Kg}$ \\
\hline$m 1-m 2$ & Front-left and front-right tire mass respectively & 40 & $\mathrm{Kg}$ \\
\hline$m 3-m 4$ & Rear-left and Rear-right tire mass respectively & 35.5 & $\mathrm{Kg}$ \\
\hline$J x$ & Moment of inertia $x$-direction & 460 & $\mathrm{Kg} \cdot \mathrm{m}^{2}$ \\
\hline$J y$ & Moment of inertia $y$-direction & 2460 & $\mathrm{Kg} \cdot \mathrm{m}^{2}$ \\
\hline$l_{1}$ & Distance between the center of gravity of vehicle body and front axle & 1.011 & $\mathrm{~m}$ \\
\hline$l_{2}$ & Distance between the center of gravity of vehicle body and rear axle & 1.803 & $\mathrm{~m}$ \\
\hline$b$ & Width of track & 1.51 & $\mathrm{~m}$ \\
\hline
\end{tabular}

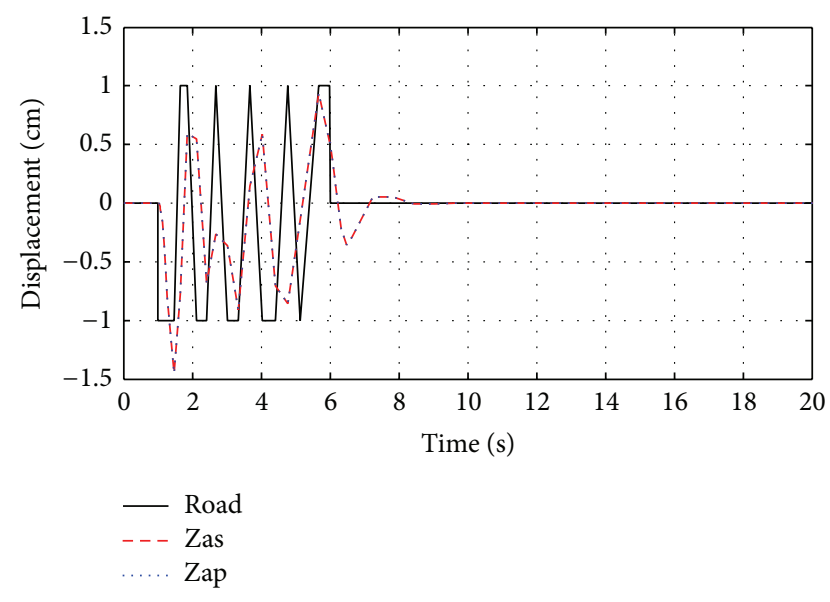

FIGURE 8: The response of optimization technique with square wave road profile.

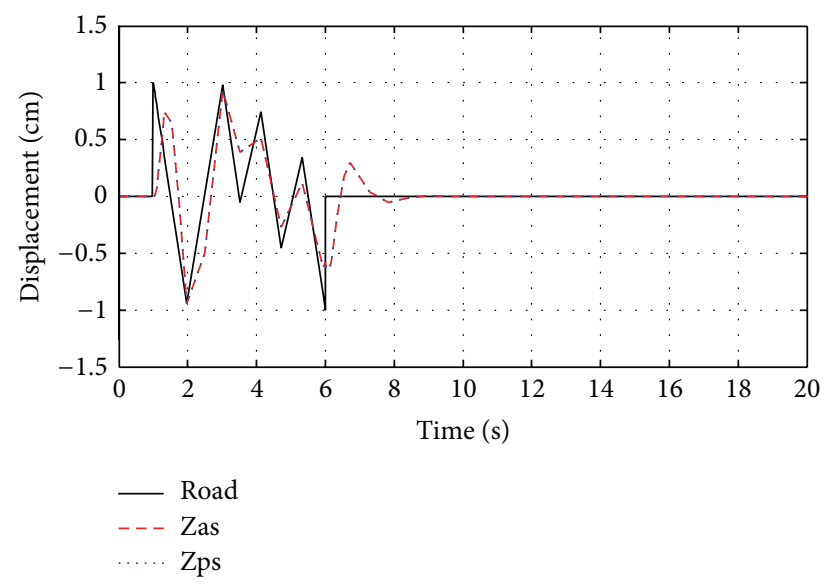

FIgURE 9: The response of optimization technique with saw tooth wave road profile.

\section{Conclusion}

The optimization technique available in OptiY with SIMULINK simulation was successfully used in this paper to find the equivalent air spring suspension model with the optimized parameters. The results are shown that the equivalent model can produce the suspension response similar to the passive suspension system. In future studies, the model can be used in active air suspension system design for better handling and stability properties. The nature of low resonance frequency in air spring can be exploited by frequency domain controller design methods such as $\mathrm{H} \infty$ methods [28].

\section{Conflict of Interests}

The authors declare that they have no conflict of interests regarding the publication of this paper.

\section{References}

[1] H. M. Zheng, L. H. Zhu, and N. D. D. Dong, "Investigation on on-off damping control law of vibration isolator," in Proceedings of the International Conference on Mechanics and Materials Engineering (ICMME '14), pp. 176-182, Phuket Island,Thailand, October 2014.

[2] B. Chandekar and H. D. Lagdive, "Design of electro-hydraulic active suspension system for four wheel vehicles," International Journal of Emerging Technology and Advanced Engineering, vol. 4, no. 4, pp. 885-889, 2014.

[3] D. P. Krishnasamy, J. Jayaraj, and D. John, "Experimental investigation on road vehicle active suspension," Journal of Mechanical Engineering, vol. 59, no. 10, pp. 620-625, 2013.

[4] C. M. Harris and A. G. Piersol, Eds., Harris' Shock and Vibration Handbook, McGraw-Hill, New York, NY, USA, 5th edition, 2002. 
[5] V. Gavriloski, E. Vetadzokoska, N. Babamov, and J. Jovanova, "Development of air spring dynamic model for vehicle suspension," Mechanical Engineering-Scientific Journal, vol. 28, no. 2, pp. 89-94, 2009.

[6] M. Presthus, Derivation of air spring model parameters for train simulation [M.S. thesis], Lulea University of Technology, 2002.

[7] Air Suspension Conversion Systems, http://www.suncoreindustries.com/suspension-conversion-systems.php.

[8] (n.d.), October 2014, Suspension-Alternative.com, http:// suspensionalternatives.wordpress.com.

[9] eCustomhitch, (n.d.), 2014, http://ecustomhitch.com.

[10] http://unityautomotive.co.

[11] Arnott Europe Air Suspension Products, 1989, https://www .arnotteurope.com.

[12] Air Left Suspension, Air Suspension, 1999, http://www .airsuspension.com.

[13] K. Toyofuku, C. Yamada, T. Kagawa, and T. Fujita, "Study on dynamic characteristic analysis of air spring with auxiliary chamber," JSAE Review, vol. 20, no. 3, pp. 349-355, 1999.

[14] S. Y. Bhave, "Effect of connecting the front and rear air suspensions of a vehicle on the transmissibility of road undulation inputs," Vehicle System Dynamics, vol. 21, no. 4, pp. 225-245, 1992.

[15] D. A. Crolla and M. Ramsbottom, Development and Analysis of a Prototype Controllable Suspension, SI: Society of Automotive Engineers, Warrendale, Pa, USA, 1997.

[16] J. Xiao, B. T. Kulakowski, and M. Cao, "Active air-suspension design for transit buses," International Journal of Heavy Vehicle Systems, vol. 14, no. 4, pp. 421-440, 2007.

[17] J. Wu, W. Shangguan, and X. Pan, "Computational method for dynamic properties of rubber isolators using hyperelasticviscoelastic-plastoelastic constitutive model," Journal of Mechanical Engineering, vol. 46, no. 14, pp. 109-114, 2010.

[18] V. Bhandari and S. C. Subramanian, "Development of an electronically controlled pneumatic suspension for commercial vehicles," in Proceedings of the IEEE International Conference on Power, Control and Embedded Systems (ICPCES '10), December 2010.

[19] S. Bruni, J. Vinolas, M. Berg, O. Polach, and S. Stichel, "Modelling of suspension components in a rail vehicle dynamics context," Journal of Vehicle System Dyanmics, vol. 49, no. 7, pp. 1021-1072, 2011.

[20] L. Liu and W. Z. Li, "Research on stiffness of air-spring with auxiliary chamber and its equivalent model," in Proceedings of the 11th International Conference on Vibration Problems, Z. Dimitrovová, J. R. de Almeida, and R. Gonçalves, Eds., pp. 1-8, Lisbon, Portugal, 2013.

[21] S. Eaton, A Mathematical Model of a Nonlinear Pneumatic Suspension System, ABB Daimler-Benz Transportation (Rolling Stock), Berlin, Germany, 1997.

[22] D. Vannucci, G. Saporito, and M. Romani, "Wheel rail dynamic of DMU IC4 car for DSB: modelling of the effect of secondary air spring on calculation results and advanced analysis for controlling car body angle," in Proceedings of the SIMPACK User Meeting, March 2006, http://www .simpack.com/fileadmin/simpack/doc/usermeeting06/um06_ ansaldob-saporito.pdf.

[23] M. Berg, "A three-dimensional air spring model with friction and orifice damping," in Proceedings of the 16th IA VSD Symposium, the Dynamics of Vehicles on Roads and on Tracks, Pretoria, South Africa, 1999.
[24] M. Berg, "An air spring model for dynamic analysis of rail vehicles," TRITA-FKT Report 1999:32, Division of Railway Technology, Department of Vehicle Engineering, Royal Institute of Technology, Stockholm, Sweden, 1999.

[25] P. Sundvall, "Comparisons between predicted and measured ride comfort in trains-a case study on modeling," TRITAFKT Report, Division of Railway Technology, Department of Vehicle Engineering, Royal Institute of Technology, Stockholm, Sweden, 2001.

[26] S. Shahriar, Development and evaluation of a semi-active suspension system for full suspension tractors [Ph.D. thesis], Technische University Berlin, 2009.

[27] A. A. Aldair, Neurofuzzy controller based full vehicle nonlinear active suspension systems [Ph.D. thesis], School of Engineering and Informatics, University of Sussex, Brighton, UK, 2012.

[28] W. Sun, H. Gao, and O. Kaynak, "Finite frequency $H_{\infty}$ control for vehicle active suspension systems," IEEE Transactions on Control Systems Technology, vol. 19, no. 2, pp. 416-422, 2011. 

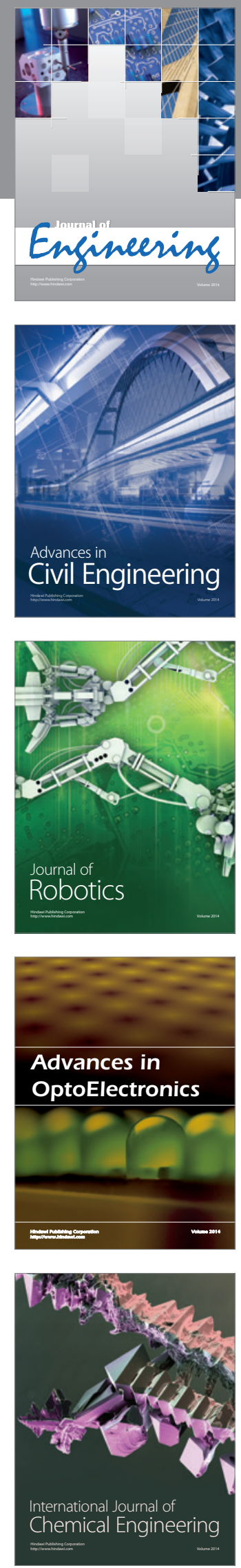

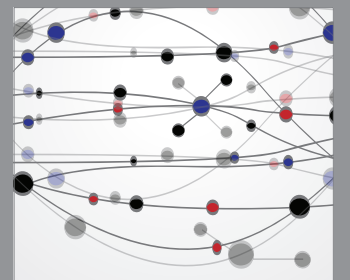

The Scientific World Journal
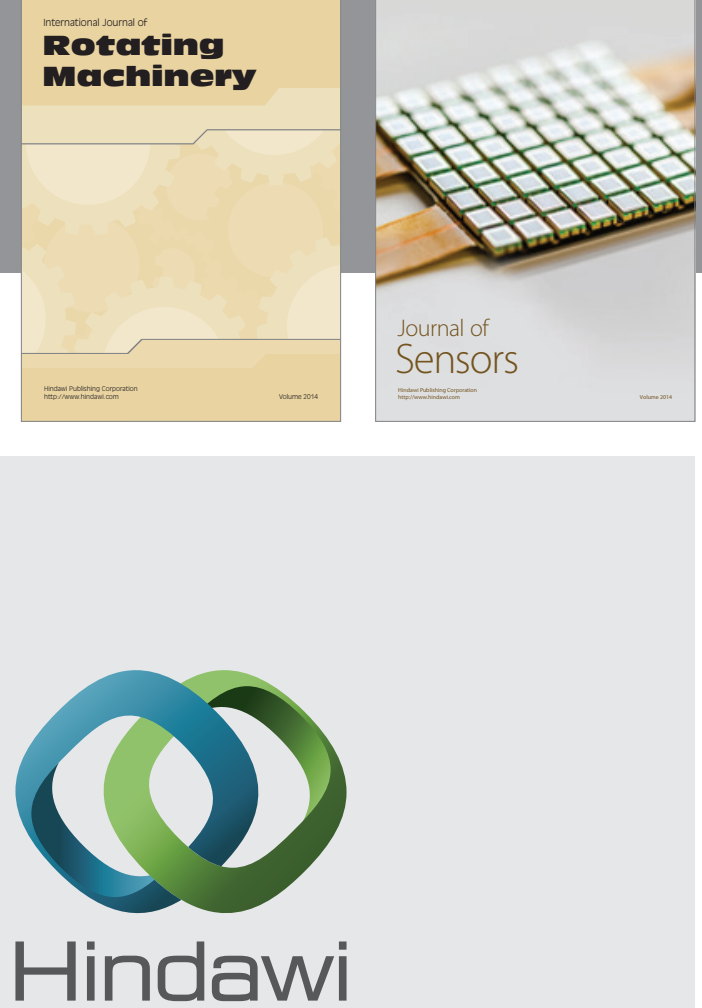

Submit your manuscripts at http://www.hindawi.com
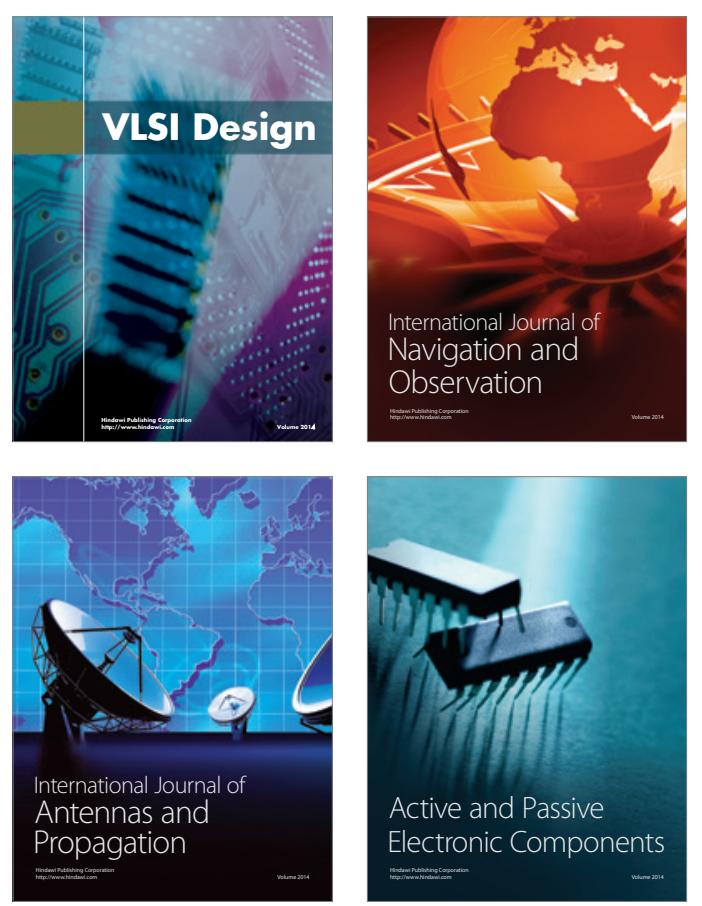
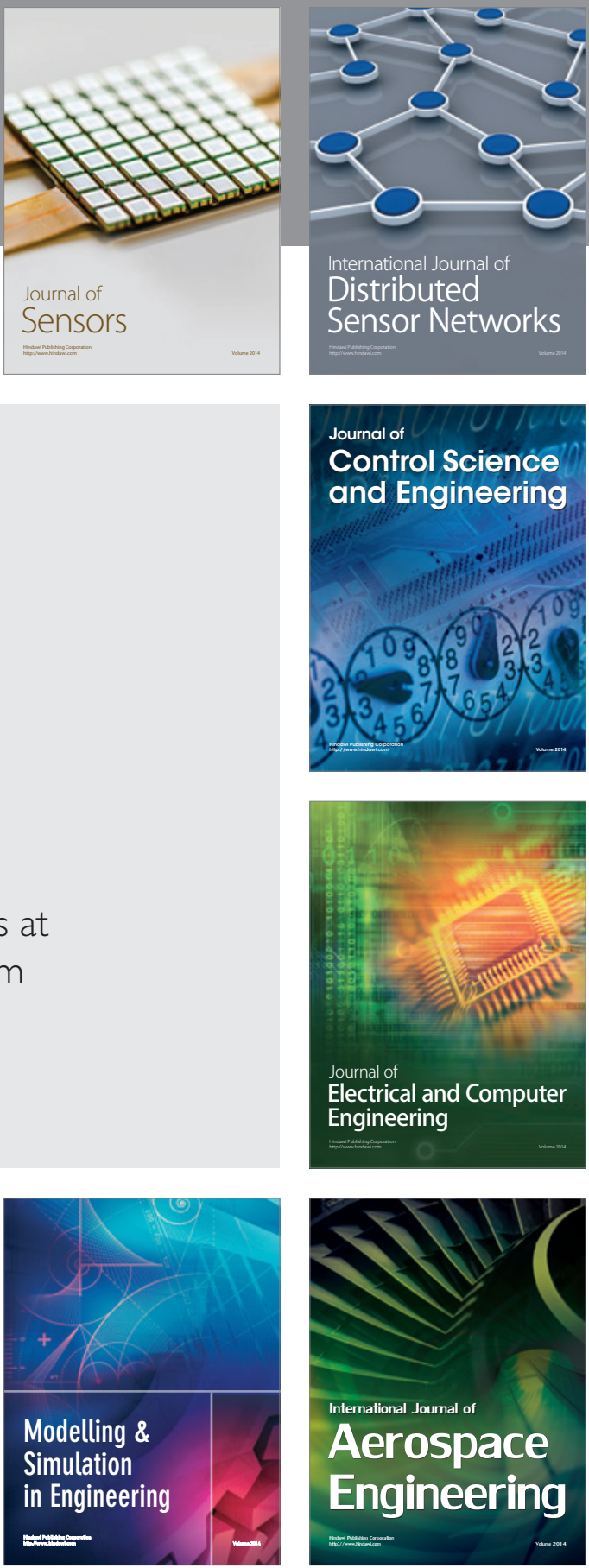

Journal of

Control Science

and Engineering
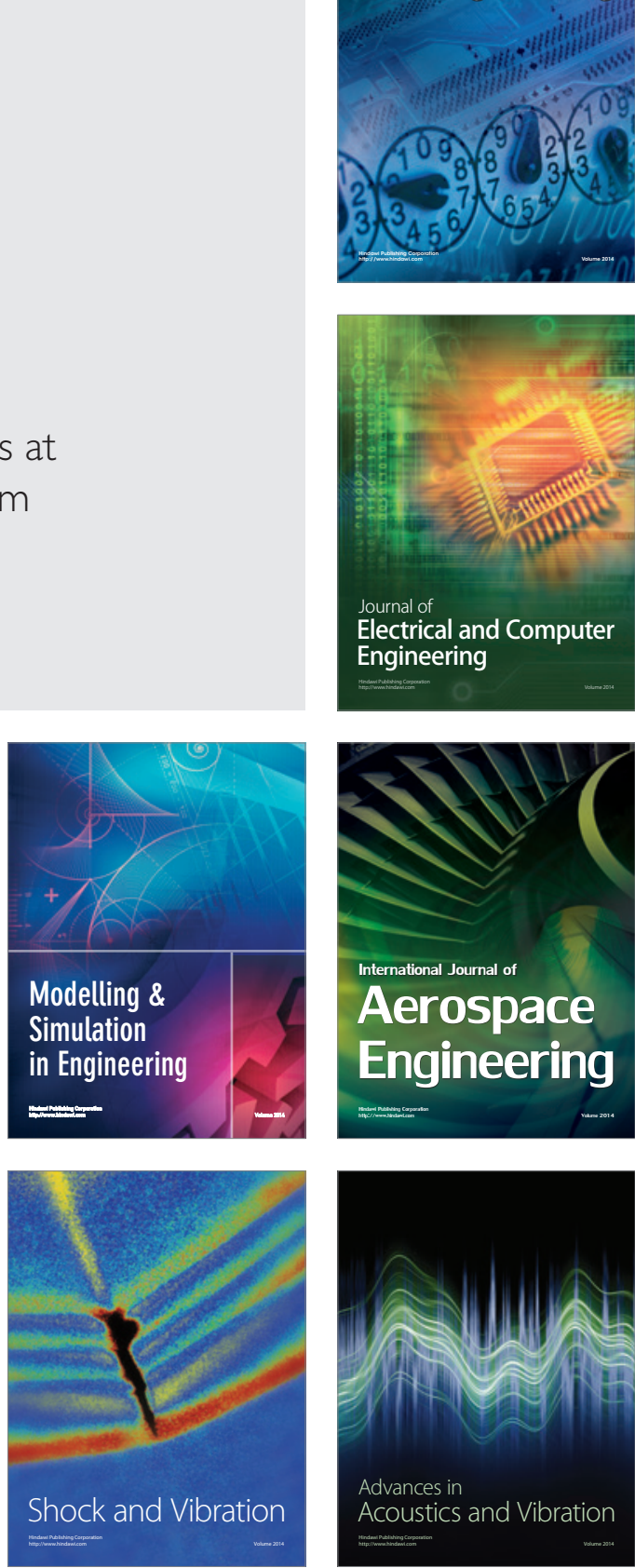